\title{
EDUCAÇÃO INCLUSIVA NA EDUCAÇÃO A DISTÂNCIA: PERCEPÇÕES DE TUTORES FRENTE À MEDIAÇÃO COM OS ALUNOS PÚBLICO ALVO DA EDUCAÇÃO ESPECIAL
}

https://doi.org/10.29327/3860.11.19-4

\author{
Natália Gomes dos Santos ${ }^{1}$ \\ Lilian Amaral da Silva Souza ${ }^{2}$ \\ Bruno Cézar Scaramuzza ${ }^{3}$ \\ Melina Klaus ${ }^{4}$
}

\section{RESUMO}

O presente estudo teve como objetivo analisar as contribuições de um curso de capacitação sobre a Educação Inclusiva na Educação a Distância $(\mathrm{EaD})$ para tutores que atuam no ensino superior e compreender as percepções dos tutores frente ao trabalho realizado com os alunos público alvo da educação especial na mediação pedagógica. Por meio das legislações atuais e das discussões sobre a democratização do ensino, observa-se que a educação especial é uma modalidade transversal que perpassa todos os níveis, modalidades e etapas de ensino. Nesta lógica, devem ser garantidas as condições de acesso, permanência e sucesso acadêmico. No que se refere ao ensino superior, observa-se que houve um aumento significativo de alunos com necessidades educacionais especiais. Também são verificadas as contribuições das Tecnologias da Informação e Comunicação (TICs) para o sucesso acadêmico desses alunos e por esta questão a modalidade EaD auxilia na formação de nível superior. Por conta desse contexto foram analisadas, com base na abordagem qualitativa, as percepções de tutores que

\footnotetext{
${ }^{1}$ Licenciada em Educação Especial pela Universidade Federal de São Carlos e Mestre em Educação pela Universidade Estadual de Londrina. Professora do curso de Pedagogia em EaD na UNIVERSIDADE PITÁGORAS UNOPAR

${ }^{2}$ Licenciada em Pedagogia pelo Centro Universitário Filadélfia - UNIFIL e Mestre em Metodologias para o Ensino de Linguagens e suas Tecnologias pela Universidade Pitágoras-UNOPAR. Coordenadora do curso de Pedagogia em EaD na UNIVERSIDADE PITÁGORAS UNOPAR

${ }^{3}$ Graduado em Administração de Empresas e Mestre em Metodologias para o Ensino de Linguagens e suas Tecnologias pela Universidade Pitágoras-UNOPAR. Coordenador Acadêmico na modalidade EaD da UNIVERSIDADE PITÁGORAS UNOPAR

${ }^{4}$ Licenciada em Pedagogia e Mestre em Educação pela Universidade Estadual de Londrina. Gerente Acadêmico na modalidade EaD da UNIVERSIDADE PITÁGORAS UNOPAR.
} 
Revista Científica de Educação a Distância

Vol.11 - №19 - JANEIRO - 2019 - ISSN: 1982-6109

realizam o trabalho de mediação pedagógica a partir de um curso de formação ofertado por uma universidade privada. Participaram do estudo nove tutores que atuam no curso de pedagogia. Os resultados apontaram que os tutores compreendem a importância de um trabalho com base em adaptações e estratégias, visando propiciar o acesso ao conhecimento para os alunos. Também foi colocado pelos participantes que o olhar deve estar voltado para as barreiras sociais que dificultam os estudos desse público no ensino superior. Por meio do estudo foi possível constatar a necessidade dessas discussões com todos os envolvidos no processo de inclusão dos alunos público alvo da educação especial, visto que o acesso ao ensino e a qualificação profissional é um direito social.

Palavras-chave: Inclusão; Ensino Superior; Educação a Distância.

\title{
INCLUSIVE EDUCATION IN DISTANCE EDUCATION: THE PERSPECTIVE OF TUTORS MEDIATING SPECIAL EDUCATION STUDENTS
}

\begin{abstract}
The following paper aimed to analyze the contributions of a training course on Inclusive Education in Distance Education offered to higher education tutors and to understand their perceptions regarding the work carried out with the target public of special education in pedagogical mediation. Considering the current legislation and discussions on the democratization of education, Special Education is a transversal modality of education that permeates all levels, modalities and stages of the schooling process. Therefore, the conditions of access, permanence and academic success must be guaranteed. Regarding higher education, there has been a significant increase in students with special educational needs. Many are the contributions of Information and Communication Technologies (ICTs) to the academic success of these students, thus distance education may be seen as a tool to provide access to a degree in higher education. In this context, during a training course, the perceptions of tutors who work with pedagogical mediation in a private university were analyzed based on the qualitative approach. Nine tutors who participated in the training course participated in the study. The results showed that tutors understand the importance of a work based on adaptations and strategies, aiming to provide access to knowledge to students. Participants also pointed out that the approach must be focused on the social barriers imposed to the public of Special Education to study in higher education. The study highlighted the importance of such discussions with all those involved in the process of inclusion of the target public students of special education, since access to education and professional qualification is a social right.
\end{abstract}

Keywords: Inclusion; Higher Education; Distance Education. 
Vol.11 - №19 - JANEIRO - 2019 - ISSN: 1982-6109

\section{INTRODUÇÃO}

Com base nas discussões possibilitadas no final do século $\mathrm{XX}$, a educação começou a ser observada pelo viés da democratização do ensino. Assim, todos possuem o direito ao acesso à educação de qualidade, sem vestígios de discriminação e preconceitos (KASSAR, 2011).

Tais discussões também impulsionaram os debates sobre a educação inclusiva, propiciando ao público alvo da educação especial o direito ao acesso, permanência e qualidade do ensino gratuito e regular. No Brasil as políticas começaram a ser implementadas para que esse direito se efetive na realidade. Desta forma em 2008 foi instituída a Política Nacional de Educação Especial na Perspectiva da Educação Inclusiva, a qual apresenta a educação especial como uma modalidade transversal que perpassa todos os níveis, etapas e demais modalidades educacionais (BRASIL, 2008).

Dentre as finalidades apresentadas nesta política, encontra-se a de assegurar o acesso dos alunos com deficiência, transtornos globais do desenvolvimento e altas habilidades/superdotação desde a educação infantil até o ensino superior. Esses indivíduos também devem ter a garantia de serviços de Atendimento Educacional Especializado (AEE), os quais podem ser de caráter complementar e/ou suplementar (BRASIL, 2008).

Nesse contexto, observa-se a necessidade de se discutir as condições de ingresso e permanência dos alunos público alvo da educação especial em diferentes espaços de ensino, inclusive no Ensino Superior, visto que estudos apontam um significativo aumento de matrículas dos alunos com necessidades educacionais especiais (NEE) nesse nível. Apesar dos avanços, encontra-se a necessidade de ampliar e oportunizar a inserção dos alunos com NEE no ensino superior, pois segundo os indicadores educacionais organizados pelo INEP/MEC, analisados entre 2004 e 2014, foi possível observar que apenas 0,37\% dos alunos que se encontravam no ensino superior possuíam alguma especificidade desse público alvo (PLETSCH; LEITE, 2017).

Em relação as oportunidades de ofertada ao Ensino Superior, observa-se que a mesma pode ser realizada na modalidade a distância, a qual se configura como possiblidade 
Vol.11 - №19 - JANEIRO - 2019 - ISSN: 1982-6109

de expansão do Ensino Superior. Para se compreender as perspectivas de educação ofertada para esse público, na modalidade de Educação a Distância (EaD), esse artigo tem como objetivo analisar as contribuições de um curso de capacitação sobre a Educação Inclusiva na $\mathrm{EaD}$ para tutores que atuam no ensino superior e compreender as percepções dos tutores frente ao trabalho realizado com os alunos público alvo da educação especial na mediação pedagógica.

\section{O ACESSO AO ENSINO SUPERIOR PELO PÚBLICO ALVO DA EDUCAÇÃO ESPECIAL E AS POSSIBILIDADES DA EAD NESSE PROCESSO}

A década de 1990 marcou a área da educação especial, visto que nesse momento se iniciaram as primeiras discussões sobre o direito à educação deste público na educação brasileira. Por meio de dois eventos realizados pelos organismos internacionais, Conferência de Educação para Todos (1990) e Conferência Mundial de Educação Especial (1994), novas reflexões foram se constituindo, de modo que a educação das pessoas com deficiência foi debatida em uma perspectiva inclusiva, a qual deveria oportunizar para esse público acesso, permanência e sucesso acadêmico (MENDES, 2010).

Neste contexto, o Brasil adere às normativas internacionais e começa a organizar suas políticas de modo que assegure aos alunos com deficiência, transtornos globais do desenvolvimento e altas habilidades/superdotação acesso ao ensino regular e inclusivo. Dentre as legislações atuais que respaldam o trabalho realizado com esses sujeitos, encontra-se a Política Nacional de Educação Especial na Perspectiva da Educação Inclusiva (2008). Por meio desse documento verifica-se que a educação especial se configura como:

[...] uma modalidade de ensino que perpassa todos os níveis, etapas e modalidades, realiza o atendimento educacional especializado, disponibiliza os recursos e serviços 
Vol.11 - №19 - JANEIRO - 2019 - ISSN: 1982-6109

e orienta quanto a sua utilização no processo de ensino e aprendizagem nas turmas comuns do ensino regular (BRASIL, 2008, s/p).

Por meio dessa política, observa-se que os alunos com NEE possuem o direito ao acesso à todos os níveis de ensino, inclusive ao superior. Nesta lógica, a inserção ao ensino superior começou a se intensificar, como consta nos indicadores educacionais brasileiros, a partir do aumento significativo de matrículas.

Por conta desse cenário o acesso do público alvo da educação especial ao ensino superior aumentou. A universidade é um espaço por excelência, visto que nela é produzida e discutida a produção do conhecimento científico. Esse saber se configura como legado humano e deve ser apropriado por todos os indivíduos, independentemente de suas necessidades e especificidades. Segundo Santos et al. (2015), a inclusão no ensino superior é produto de múltiplos fatores e por este fato deve-se compreender a importância da implementação e efetivação das políticas públicas que favorecem a concretização do ensino, tendo como foco o respeito e entendimento das diferenças.

Outra discussão que deve ser articulada com as políticas voltadas à inclusão no ensino superior é a necessidade de acessibilidade desse público. Temos normativas que defendem não apenas o acesso ao ensino, mas também a permanência e o sucesso escolar, e deste modo o sujeito deve ter condições, em todas as esferas, para se apropriar do saber científico. Para que isso aconteça as especificidades dos tipos de necessidades educacionais especiais devem ser atendidas, de modo que o Ministério da Educação (MEC) monitore esse processo, tanto nas instituições privadas quanto públicas (ROCHA; MIRANDA, 2009).

Nesta ótica, a Lei $\mathrm{n}^{\mathrm{o}} 10.098$ de 2000 apresenta critérios para a efetivação da acessibilidade, apresentando que esse conceito se refere às possiblidades de acesso, com autonomia e segurança aos diversos espaços, materiais, equipamentos, meio de comunicação e transportes para locomoção de pessoas com mobilidade reduzida e deficiência (BRASIL, 2000).

Outro aspecto que influência as possiblidades de inserção desse público no ensino superior são as Tecnologias de Comunicação e Informação (TICs). Segundo Rodrigues (2013, p. 39): 
Vol.11 - №19 - JANEIRO - 2019 - ISSN: 1982-6109

As TIC em tempo de Educação Inclusiva são uma oportunidade para respeitar identidades e para criar ambientes de aprendizagem em cada aluno tenha a possibilidade de se sentir útil e participativo. Precisamos assim de desenvolver um pensamento proactivo sobre as TIC; isto é, não pensar nas TIC como um tsunami que tudo arrasa no seu caminho mas antes como um fértil e criativo curso de água que, conforme a forma como o dirigirmos, poderá irrigar e ajudar a florescer a Educação do século XXI numa perspectiva de dignificação e construção de oportunidades de igualdade para todos os alunos.

Verifica-se a relevância do Ensino Superior na modalidade a distância para esse público, visto que, com auxílio das TICs são ampliadas as condições de ingressar e permanecer nesse nível de ensino. Ao realizar um levantamento do acesso desse público na EaD não foram encontrados trabalhos, sendo assim nota-se a necessidade de se refletir sobre essa realidade.

Sabe-se que a educação a distância propicia ampliação das possiblidade de estudo, visto que por meios digitais o aluno tem acesso aos conhecimentos necessários para sua formação. É importante desconstruir qualquer concepção equivocada sobre essa modalidade, visto que a diferença entre a modalidade a distância e presencial se encontra na flexibilidade de horários para o estudo. Respaldada pelo Decreto 5.622/2005, a EaD deve cumprir com a carga horária estipulada pelos cursos de graduação, apresentadas nas Diretrizes Curriculares dos cursos. Nesta lógica, observa-se que:

\footnotetext{
Educação a distância é o aprendizado planejado que ocorre normalmente em um lugar diferente do local do ensino, exigindo técnicas especiais de criação do curso e de instrução, comunicação por meio de várias tecnologias e disposições organizacionais e administrativas especiais. Os principais aspectos a serem enfatizados a respeito dessa definição indicam que nosso estudo de educação a distância é um estudo de:

- Aprendizado e ensino

- Aprendizado que é planejado, e não acidental;

- Aprendizado que normalmente está em um lugar diferente do local de ensino;

. Comunicação por meio de diversas tecnologias. (MOORE; KEARSLEY, 2013, p. 2)
}

Para que os estudos desenvolvidos na educação a distância tenha êxito, é essencial o trabalho de mediação realizado pelos professores e tutores. Essa mediação se constitui por meio de diferentes ferramentas digitais, as quais propiciam interatividade e diálogo entre os profissionais e os alunos. A mediação ocorre no Ambiente Virtual de Aprendizagem (AVA), no qual o aluno participa dos fóruns de discussão, que propiciam o debate e a reflexão das 
Vol.11 - №19 - JANEIRO - 2019 - ISSN: 1982-6109

temáticas abordadas nas aulas. Outra ferramenta é o sistema de mensagens em que o aluno envia suas dúvidas e informações são socializadas pelos tutores. Encontra-se no ambiente a sala do tutor que se configura como um espaço de comunicação sobre assuntos pedagógicos. Nesta ferramenta é disponibilizada as orientações de todas as disciplinas, materiais complementares para aprofundamento dos estudos e informações sobre as produções textuais. Outro recurso disponibilizado é o chat, o qual oportuniza interatividade em tempo real entre professores, tutores e alunos (BESSA, 2017).

$\mathrm{Na}$ interface inclusão e EaD o trabalho de mediação do tutor é crucial no processo, visto que ele dará suporte para os alunos em suas atividades acadêmicas. Por esse fator é necessário que esse profissional tenha conhecimentos específicos sobre a educação especial e as estratégias que oportunizam a efetivação do ensino desse alunado. Por tais questões observa-se a relevância desse estudo, pois propicia novas reflexões sobre formas de estratégias para que o direito ao ensino superior se concretize na $\mathrm{EaD}$.

\section{CAMINHOS METODOLÓGICOS PERCORRIDOS}

O presente estudo é de cunho qualitativo, visto que sua finalidade foi compreender a percepção de um grupo de tutores frente a realização de um curso de capacitação sobre a inclusão na EaD. Observa-se as contribuições dessa abordagem, pois possibilita ao pesquisador apreender a realidade, capturando as nuances e os sentidos atribuídos pelos participantes. Essa abordagem propicia uma análise aprofundada sobre o contexto e as implicações, relações, ações e significados que se encontram na realidade estudada.

Com base nessa abordagem, optou-se pela análise de discurso, visto que

"a linguagem como mediação necessária entre o homem e a realidade natural e social. Essa mediação, que é o discurso, torna possível tanto a permanência e a continuidade quanto o deslocamento e a transformação do homem e da realidade em que ele vive. O trabalho simbólico do discurso está na base da produção da existência humana" (ORLANDI, 1995, p. 15)

Por essa questão, o ato de oportunizar aos tutores a socialização de suas percepções faz com que eles reflitam sua prática e as perspectivas de melhoria da mesma. Nessa lógica, os tutores puderam, por meio de um formulário online, expor suas impressões tanto sobre o 
Vol.11 - №19 - JANEIRO - 2019 - ISSN: 1982-6109

impacto do curso de capacitação intitulado "Educação Inclusiva na EaD” no trabalho com a mediação pedagógica quanto o seu olhar frente à educação em nível superior do público alvo da educação especial.

A pesquisa se deu em uma universidade privada de grande porte, que oferta $\mathrm{EaD}$, a qual possui alunos em diversos cursos de graduação que residem em todos os estados brasileiros. Por conta da democratização do acesso ao ensino superior, essa instituição possui políticas de inclusão, contando com um setor específico que oportuniza assistência técnica e pedagógica para alunos, professores e profissionais dos polos presenciais. O curso de capacitação foi ministrado por uma docente da instituição que possui formação específica na área da educação especial.

A capacitação aconteceu com todos os tutores da instituição e se deu por meio de videoaula e leituras de artigos, além de questões reflexivas para que os tutores aprofundassem seus conhecimentos. As principais temáticas abordadas no curso foram: conhecimentos sobre as possibilidades da educação inclusiva na educação a distância, entendimento sobre como se configura o Atendimento Educacional Especializado e apropriação de estratégias e recursos para a efetivação dos estudos do púbico alvo da educação especial na educação a distância. $\mathrm{O}$ enfoque do curso era o trabalho realizado pelo tutor no processo de mediação.

Após a realização do curso, foram convidados nove tutores do curso de pedagogia para participar do estudo. O critério para a escolha se deu pelo fato deste curso de graduação atender o maior número de alunos da instituição.

Foi encaminhado para os mesmos um formulário online com nove questões dissertativas, as quais abordavam temáticas como: formação pedagógica do tutor, trabalho com o público alvo da educação especial, conhecimento sobre políticas inclusivas, desafios e possiblidades do trabalho com os alunos com necessidades educacionais especiais e o olhar para a atuação após a realização do curso de capacitação.

\section{PERCEPÇÕES DE TUTORES A DISTÂNCIA FRENTE AO TRABALHO COM O PÚBLICO ALVO DA EDUCAÇÃO ESPECIAL}


Vol.11 - №19 - JANEIRO - 2019 - ISSN: 1982-6109

No presente estudo foram coletadas informações de nove tutores que atuam no curso de pedagogia, os quais compartilharam suas impressões e reflexões sobre as perspectivas e desafios do trabalho realizado com o público alvo da educação especial, a partir de formação em serviço, por meio de curso de capacitação e sua própria prática na mediação pedagógica.

Dos nove tutores, todos são formados em pedagogia. Oito são do sexo feminino e um do sexto masculino. Outra informação interessante é que quatro tutores já trabalharam diretamente com alunos público alvo da educação especial em outras atuações profissionais e cinco não tiveram essa experiência. Dos profissionais que tiveram experiência com o público alvo da educação especial, observou-se que os mesmos reconhecem a necessidade da busca de novos conhecimentos para atuarem na área, também pontuaram o entendimento de que as pessoas com necessidades educacionais especiais possuem especificidades, as quais devem ser respeitadas. Uma colocação relevante é que conforme eles foram conhecendo mais sobre a especificidade dos alunos novas estratégias foram sendo criadas para desenvolver o trabalho com o público.

Ao serem questionados sobre o conhecimento de políticas que respaldam o direito do público alvo da educação especial ao ensino superior, todos os tutores relataram que tiveram acesso as legislações por meio dos cursos ofertados pela instituição, apenas dois tutores pontuaram que estudaram a temática no curso de formação inicial. Apesar da instituição, em que esses tutores atuam, ofertar formação em serviço sobre a educação especial, observa-se um desafio frente a formação inicial de pedagogos sobre a área, visto que foram poucas discussões propiciadas para esses profissionais em sua formação inicial, as quais não oportunizaram uma compreensão mais aprofundadas das políticas que asseguram o direito dos alunos com necessidades educacionais especiais ao ensino superior. Nesta lógica, observa-se que:

A educação inclusiva coloca-se, hoje, como um desafio tanto para a formação inicial quanto para a formação continuada do professor. Portanto, é preciso que essa formação compreenda e considere esse contexto, a fim de empreender um processo de formação de profissionais da educação críticos e conscientes das relações entre a sociedade e a escola, bem como de suas potencialidades de participação na transformação social, com vistas à construção de uma sociedade mais justa e igualitária (DEIMLING, 2013, p. 248). 
Vol.11 - №19 - JANEIRO - 2019 - ISSN: 1982-6109

Ao serem questionados sobre as possibilidades e desafios da inclusão desse público na $\mathrm{EaD}$, os tutores pontuaram a necessidade de adaptações em todas as esferas (espaço físico, mobiliário, e ou material pedagógico) para que eles possam se apropriar do conhecimento científico. Também pontuaram a relevância de conhecer, à priori, as necessidades para adaptar e disponibilizar os materiais de forma adequada. Um tutor aponta a necessidade de capacitação constante para que o processo se efetive, também é apresentado como desafio as dificuldades de identificação do público alvo para um trabalho mais especializado.

Outro apontamento relevante é a compreensão que um tutor expressou sobre o fato das barreiras se constituírem como desafios para a efetivação do sucesso acadêmico desse alunado. Quando se analisa essa colocação, comparando-a com o conceito de deficiência apresentado na legislação, observa-se a importância de considerar as barreiras, visto que as pessoas com deficiência são compreendidas como "aquelas que têm impedimentos de longo prazo de natureza física, mental, intelectual ou sensorial, os quais, em interação com diversas barreiras, podem obstruir sua participação plena e efetiva na sociedade em igualdades de condições com as demais pessoas". (BRASIL, 2009, s/p - grifo nosso).

Dessa forma a deficiência não pode ser observada apenas nas especificidades do sujeito, mas também nas barreiras sociais que devem ser eliminadas para que os indivíduos tenham acesso a espaços e serviços ofertados na sociedade. Os alunos com necessidades educacionais especiais que estudam no Ensino Superior na EaD possuem totais condições de aprendizagem e para que isso se efetue é indispensável o entendimento de que todos os envolvidos no processo (professores, coordenadores e tutores) tenham o conhecimento sobre a responsabilidade de seu papel para que isso se efetive.

Outro aspecto apontado como possibilidade de inclusão desse alunado na EaD é a utilização das TICs. Isto pode ser observado no apontamento de um tutor:

"A possibilidade de acesso a um curso superior através de plataformas digitais é muito importante na atualidade, ainda mais quando o público é de Educação Especial, haja visto que as dificuldades, dependendo do grau de deficiência, permitem uma limitação do aluno no ingresso as Universidades presenciais, tais como: deslocamento, acessibilidade entre outros. Na EaD as possibilidades são mais acessíveis para o aluno cursar a graduação. (T2) 
Vol.11 - №19 - JANEIRO - 2019 - ISSN: 1982-6109

Em relação ao curso de capacitação, os tutores foram questionados se o mesmo oportunizou ampliação de seus conhecimentos na área da educação especial. De forma unânime, os tutores pontuaram que novos saberes foram adquiridos com o curso. Eles colocaram que por meio do curso foi possível refletir sobre a necessidade de olhar para a pessoa com deficiência para além de suas especificidades. Também relataram que o curso apresentou as características das diferentes necessidades e o modo como proceder, de forma prática, no atendimento a este público, por meio de adaptações. Também colocaram a relevância de superar paradigmas e preconceitos em relação a aprendizagem desse público. Segundo uma tutora:

"De acordo com o curso "Educação Inclusiva na EaD”, quando falamos em inclusão no ensino superior, estamos falando da eliminação de barreiras de acessibilidade. É necessário garantir o acesso para que todos os alunos possam desenvolver seus estudos com autonomia, buscando atingir os objetivos do curso a fim de garantir sua formação. Através do curso, foi possível aprender que a deficiência não se constitui como doença ou invalidez e que as políticas sociais, destinadas a este grupo populacional, não se restringem às ações de caráter clínico e assistencial e que a efetivação do direito à educação requer estratégias eficazes de enfrentamento dos desafios que se interpõem durante o processo de construção dos sistemas educacionais inclusivos (T1).

O que chamou a atenção, tanto na fala dessa tutora como nas demais, é a compreensão de que a forma como a deficiência é discutida e entendida deve ser mudada. Ao se analisar o conceito de deficiência, por meio da perspectiva histórico cultural apresentado por Vygotsky, é possível observar que as pessoas com deficiência possuem totais condições de aprender e se desenvolver, desde que o meio social em que elas estão inseridas propiciem, a partir de vias alternativas, compensação sociopsicológica. Por isso que quando se discute deficiência e possibilidades de inclusão não pode-se restringir os desafios apenas as necessidades biológicas do sujeito, mas deve-se olhar para as limitações sociais:

a cegueira e a surdez como defeito físico permanecerão ainda por muito tempo na
Terra. O cego seguirá sendo cego e o surdo, surdo, mas eles deixarão de ser pessoas
com defeito, porque a deficiência é um conceito social [...] A cegueira por si só não
faz da criança uma pessoa com defeito, não é uma deficiência, quer dizer uma
insuficiência, uma menos-valia, uma enfermidade. A cegueira se converte em
deficiência só em certas condições sociais de existência do cego (VYGOTSKY,
1989, p. 60).

Em relação as estratégias apresentadas no curso para a melhoria do trabalho de mediação junto aos alunos com necessidades educacionais especiais, os tutores relataram que o curso fez com que eles observassem a necessidade de conhecer todos os serviços 
Vol.11 - №19 - JANEIRO - 2019 - ISSN: 1982-6109

disponibilizados pela universidade. Também pontuaram a relevância de se conhecer cada deficiência para realizar as adaptações. Eles afirmaram que é importante considerar as potencialidades de cada aluno e organizar o trabalho por meio delas, não enfatizando as dificuldades. Ter o acesso aos recursos que permitem os estudos no ensino superior também foi levando pelos tutores no formulário.

Por fim, ao serem questionados sobre como observam a inserção do público alvo da educação especial na vida profissional, após a conclusão do curso de graduação, os tutores pontuaram os avanços que se apresentam na realidade, por meio de políticas públicas que asseguram o direito desses sujeitos no âmbito profissional. Uma tutora relatou que por meio da apropriação de conhecimentos na graduação, os alunos com necessidades educacionais especiais poderão atuar enquanto professores com a mesma competências que os demais. Outra colocação relevante é a clareza das possibilidades de inclusão, segundo a tutora incluir não é apenas oportunizar acesso ao ensino superior ou a carreira profissional, mas sim propiciar recursos e estratégias para que os indivíduos tenham condições de estudar e exercer a carreira escolhida.

Nesse momento também é pontuado por esses profissionais a necessidade de ruptura com os obstáculo que se encontram em nossa sociedade, segundo uma tutora:

É preciso favorecer a transposição de barreiras para a aprendizagem e propiciar a participação dos alunos com igualdade de oportunidades. A inclusão das pessoas com deficiência é fundamental para a organização, tanto pela responsabilidade social quanto pela aprendizagem da equipe e por respeito a esse público. Com a lei de cotas e a promoção de acessibilidade, as organizações podem facilitar a inserção de PCDs, mas é preciso que essa inclusão seja também social, com a igualdade de oportunidades e respeito às necessidades especiais dessas pessoas. Com essas medidas, todos saem ganhando: tanto a organização quanto as pessoas com deficiência (T2, grifo da autora).

Os alunos com necessidades educacionais dos nove tutores participantes desse estudo estão cursando o licenciatura em pedagogia, ou seja, em breve serão docentes. Não encontrase na literatura da área, pesquisas que relatam sobre o trabalho docente de pessoas com deficiência. Esse dado nos apresenta uma realidade que ainda está sendo construída, visto que esse público, há algumas décadas, não tinha a garantia do ensino básico. Dessa forma, verifica-se a importância do trabalho realizado na $\mathrm{EaD}$, visto que em muitos casos torna-se a única possibilidade de acesso ao ensino superior. Tanto na fala dos tutores quanto na análise 
Vol.11 - №19 - JANEIRO - 2019 - ISSN: 1982-6109

da realidade educativa, verifica-se que ainda encontram-se muitos desafios para que esse público tenha seu direito garantido e efetivado. No entanto, foi possível perceber que a formação em serviço de todos os profissionais que atuam com esse público no ensino superior contribui para que essa construção se efetive na realidade.

\section{CONSIDERAÇÕES FINAIS}

O presente estudo teve como objetivo analisar as contribuições de um curso de capacitação sobre a Educação Inclusiva na Educação a Distância $(\mathrm{EaD})$ para tutores que atuam no ensino superior e compreender as percepções dos tutores frente ao trabalho realizado com os alunos público alvo da educação especial na mediação pedagógica. Dessa forma, foi encaminhado para nove tutores do curso de pedagogia de uma universidade privada um formulário com questões dissertativas, as quais solicitavam questões sobre o trabalho realizado pelo tutor e o impacto de um curso de formação em serviço frente à inclusão de alunos com necessidades educacionais especiais na $\mathrm{EaD}$.

Por meio da pesquisa foi possível observar que houve avanços na realidade brasileira em relação aos direitos e acesso à educação. No entanto, deve-se examinar e refletir com criticidade as condições objetivas dessa inserção, visto que ainda encontra-se a necessidade de inúmeros avanços para que isso se efetue, de fato, na realidade.

A partir das colocações dos tutores foram verificados os impactos positivos de formação continuada em serviço, visto que muitos deles não tiveram acesso às normativas e práticas que auxiliam e asseguram as possiblidades de inclusão desse público no ensino superior. Também foi pontuado pelos participantes as contribuições das TICs, visto que ampliam as possiblidades de contato com o conhecimento científico.

Os tutores também apontaram a necessidade de considerar as potencialidades dos alunos, pois muitas vezes suas dificuldades no processo de ensino e aprendizagem se encontram nas barreiras sociais que impedem o acesso ao saber. 
Vol.11 - №19 - JANEIRO - 2019 - ISSN: 1982-6109

Como desafio foiverificado no relato dos tutores a relevância de se identificar, com precisão, as reais especificidades dos acadêmicos, para se pensar em melhorias e estratégias de mediação.

Nota-se que esse estudo contribui com as primeiras discussões sobre a temática, pois não se têm pesquisas que abordem a inclusão desse alunado na EaD. Verifica-se que essa realidade precisa ser desvelada, uma vez que a qualidade do ensino e o acesso ao conhecimento científico devem ser assegurado para todos, independentemente de suas necessidades e especificidades.

\section{REFERÊNCIAS}

BESSA, Dayane Verginia Batista. A importância da mediação ao pensar um novo modelo de tutoria. 2017. 92 f. Dissertação (Mestrado em Ensino de Linguagens e suas Tecnologias) - Universidade Pitágoras Unopar, Londrina, 2017.

BRASIL. Lei $\mathrm{n}^{\circ}$ 10.098, de 19 de dezembro de 2000. Estabelece normas gerais e critérios básicos para a promoção da acessibilidade das pessoas portadoras de deficiência ou com mobilidade reduzida, e dá outras providências. Diário Oficial da União, Brasília, DF, 20 dez. 2000.

BRASIL. Decreto ${ }^{\circ}$ 6.949, de 25 de agosto de 2009. Convenção Internacional sobre os Direitos das Pessoas com Deficiência. Disponível em: <http://www4.planalto.gov.br/legislacao>. Acesso em: 22. Jul. 2018

, Ministério da Educação (MEC). Política Nacional de Educação Especial na Perspectiva da Educação Inclusiva. Brasília. 2008a. Disponível em: http://peei.mec.gov.br/arquivos/politica_nacional_educacao_especial.pdf. Acesso em: 22. Jul. 2018.

DEIMLING, Natália Neves Macedo. A Educação Especial nos cursos de Pedagogia: Considerações sobre a formação de professores para a inclusão escolar. Educação Unisinos. n. 3 v. 17.2013 , p. $238-250$

KASSAR, Mônica de Carvalho Magalhães. Educação especial na perspectiva da educação inclusiva: desafios da implantação de uma política nacional. Educar em Revista, n. 41, Curitiba. jul./set.

2011. p. 61-79. 
Vol.11 - №19 - JANEIRO - 2019 - ISSN: 1982-6109

MENDES, Enicéia. Breve histórico da educação especial no Brasil. Revista Educación y Pedagogía, v. 22, n. 57. 2010, p. 93-110.

MOORE, M. G.; KEARSLEY, G. Educação a distância: sistemas de aprendizagem on-line. Tradução de Roberto Galman. 3. ed. São Paulo: Cengage Learning, 2013.

ORLANDI, Eni. As formas do silêncio no movimento dos sentidos. $3^{\text {a }}$ ed. Campinas: Editora da UNICAMP, 1995. p. 189.

PLETSCH, Maria Denise; LEITE, Lúcia Pereira. Análise da produção científica sobre a inclusão no ensino superior brasileiro. Educar em Revista. n. 3. v. 33. 2017, p. 87-106

ROCHA, Telma Brito; MIRANDA, Theresinha Guimarães. Cultura escolar e inclusão: A inclusão de alunos com deficiência no ensino superior: uma análise de seu acesso e permanência. In: DÍAZ, F., et al., orgs. Educação inclusiva, deficiência e contexto social: questões contemporâneas [online]. Salvador: EDUFBA, 2009.

RODRIGUÊS, David. As tecnologias de informação e comunicação em tempo de educação inclusiva. In: GIOTO, Cláudia Regina Mosca. Et al (org). As tecnologias nas práticas inclusivas. Cultura Acadêmica. Marilia. 2013.

SANTOS, Evelyn et al. Inclusão no Ensino Superior: Perceções dos estudantes com Necessidades Educativas Especiais sobre o ingresso à universidade. Revista Portuguesa de Educação, 2015, n. v. 2, Braga, 2015. p. 251-270.

VYGOTSKY, Lev Semyonovich. Fundamentos de defectologia. Obras Completas. v. 5. Havana: Pueblo y Educación, 1989.

\section{Natália Gomes dos Santos}

Licenciada em Educação Especial pela Universidade Federal de São Carlos e Mestre em Educação pela Universidade Estadual de Londrina. Professora do curso de Pedagogia em EaD na UNIVERSIDADE PITÁGORAS UNOPAR 
Vol.11 - №19 - JANEIRO - 2019 - ISSN: 1982-6109

\section{Lilian Amaral da Silva Souza}

Licenciada em Pedagogia pelo Centro Universitário Filadélfia - UNIFIL e Mestre em Metodologias para o Ensino de Linguagens e suas Tecnologias pela Universidade PitágorasUNOPAR. Coordenadora do curso de Pedagogia em EaD na UNIVERSIDADE PITÁGORAS UNOPAR

\section{Bruno Cézar Scaramuzza}

Graduado em Administração de Empresas e Mestre em Metodologias para o Ensino de Linguagens e suas Tecnologias pela Universidade Pitágoras-UNOPAR. Coordenador Acadêmico na modalidade EaD da UNIVERSIDADE PITÁGORAS UNOPAR

\section{Melina Klaus}

Licenciada em Pedagogia e Mestre em Educação pela Universidade Estadual de Londrina. Gerente Acadêmico na modalidade EaD da UNIVERSIDADE PITÁGORAS UNOPAR.

\section{Artigo recebido em 14/10/2018 Aceito para publicação em 25/01/2019}

\section{Para citar este trabalho:}

SANTOS, Natália Gomes; SOUZA, Lilian Amaral da Silva; SCARAMUZZA, Bruno Cézar; KLAUS, Melina. EDUCAÇÃO INCLUSIVA NA EDUCAÇÃO A DISTÂNCIA: PERCEPÇÕES DE TUTORES FRENTE À MEDIAÇÃO COM OS ALUNOS PÚBLICO ALVO DA EDUCAÇÃO ESPECIAL. Revista Paídéi@. Unimes Virtual. Volume 11 - Número 19 - JANEIRO - 2019 - Disponível em:

http://periodicos.unimesvirtual.com.br/index.php?journal=paideia\&page=editor \&op=submissionReview \&path[]=928 